\title{
A Survey on Food Waste Management System
}

\section{Vikram R ${ }^{\mathrm{a}}$, Anirudh $\mathbf{R}^{\mathrm{b}}$, Bhuvaneshwaran $\mathbf{M}^{\mathrm{c}}$, Praveen kumar $\mathrm{S}^{\mathrm{d}}$, Suganthkumar $\mathrm{K}^{\mathrm{e}}$}

\author{
a Department of Computer Science and Engineering ,M.Kumarasamy College of Engineering, Karur, Tamil Nadu, India -639113 \\ b,c,d,e Department of Computer Science and Engineering , M.Kumarasamy College of Engineering, Karur, Tamil Nadu, India - \\ 639113 \\ vikramr.cse@mkce.ac.in, anirudhragu210@gmail.com, bhuvaneshwaranmurugesh@gmail.com, spraveenjayan@gmail.com, \\ suganthkumaar@gmail.com
}

Article History: Received: 11 January 2021; Accepted: 27 February 2021; Published online: 5 April 2021

\begin{abstract}
Food loss or food waste is the food that is not eaten by the consumer. In addition to that bring down food waste in all role of the food organization is an main part of decreasing the environmental conditions of agriculture, by bring down the whole quantity of water, land and other external resources needed to provide the global group. Decreasing the food waste is the major part of global as it makes the food out of dumping ground. It makes profitable sight at the small scale, by reducing household food bills and at the large scale by decreasing throwing away costs for restaurants. By properly analyzeand manage the food waste makes our world to economically and environmentally healthy and make the resources available for the future generations. Everyday many students in the college wasting lots of foods. So we take an initiative to develop a web application for college used to keep track and analyze the food waste and to take a better decision by knowing what went wrong and to take the essential steps to avoid the food wastage. We planned our web application to have a login form and registration form. The dashboard has a add recipe form and remove recipe form and for wastage entries we have food waste entry form, cook waste entry form and cook item waste entry form. Our web application provides the user to generate analyzed data in table and chart format. The extra cooked recipe can be collected by the nearest Orphanages who actually requested for the food and the food waste and cook waste both were given to the agricultural land for fertilization
\end{abstract}

Keyword: Food waste , Management , Analyze

\section{Introduction}

This project is used to reduce food wastage. The main objective of our system is used to analysis and to reduce the food waste for colleges. Creating a web application that allows the user to register and login to their respective dashboard. The dashboard contains add recipe form and remove recipe form. For calculate and analyse the waste, we have three more forms which are food waste entry form, cook waste entry form and cook item entry waste form which are used to entry the total waste weights. Our web application dashboard also provides the track and analysis option which is used to generate the analysed report in table and chart format.

The application is used by three set of users

- Super Admin

- Admin

- Manager

Super Admin can able to perform all the operations done by both Admin and Manager and also, he can able to manage college registration and orphanage registrations.

Admin can able to login into their dashboard and he has an ability to activate or block the manager's account. Admin has a power to add or remove recipes for both boys and girls dining. Admin has an ability to entry the food, cook and cook item wastes for both boys and girls dining. Admin can generate the analysis report for both boys and girls dinning. Admin can able to see the full history done by every manager.

Manager can able to login into their respective dashboard if their account is in the active state. Manager can add or remove the recipes for their respective dining. Manager can able to entry the food, cook and cook item wastes for their respective dining only. Manager can generate the analysis report only for their respective dining. Manager can view their own history and not any other history.

Forms which are used in this application

- Add Recipe

- Remove Recipe 
- Food waste entry

- Cook waste entry

- Cook item waste entry

- Report generate form

Add Recipe Form is used to add the recipes for the selected dining for any selected session for the selected day.

Remove Recipe Form is used to remove the recipe from any selected dining.

Food Waste Entry Form is used to entry the total weights of the food wasted by the students on every sessions of the day.

Cook Waste Entry Form is used to entry the total weight of the vegetable wasted by the cooks during cooking.

Cook Item Waste Entry Form is used to entry the total weights of the extra cooked food which is not eaten by the students.

Report Generate Form is used to generate the report for the selected dining for the selected range of dates.

2. Technology

We are using MYSQL as our database and for backend scripting we use PHP for developing this Application. For generating the Analysis charts, we are using canvas.js and for exporting we use js.pdf libraries.

2.1 MySQL

MySQL is a open source relational database management system (RDBMS). It uses the SQL (Structured Query Language) queries for data accessing. It is the famous language for accessing and managing the data in the relational database. MySQL is currently supported by Oracle Company.

2.2 SQL

2.3 PHP

Structured query language (SQL) is a language used to get the data from the database.

PHP is a Hypertext Pre-processor. We use PHP as our backend scripting language as we use apache http server.

2.4 Canvas.js

We use canvas.js package to generate the analyze chart.

2.5 JS.pdf

We use js.pdf to generate the pdf file which contain the analyze report based on the user filter.

3. Statistics

3.1 Poverty

Poverty is a stipulation in which people or group of people not having the money and basic needs for a least level of quality such as food and shelter. Food is very essential for every people.

\subsubsection{Poverty Rate in India}

We estimate $6.7 \%$ of people in India is extending underneath at a lower level of poverty in the year 2019. It has been increased by $2.5 \%$ of people is lower level of poverty in the year 2020. In this statistic we found Chhattisgarh is the lacking sufficient to live at a standard or normal in a society. India is the $94^{\text {th }}$ rank in Global hunger Index among 107 Countries in 2019. In 2020 India ranked 102 out of 117 countries.

\begin{tabular}{|c|c|}
\hline Year & Poverty rate \\
\hline 2018 & $5 \%$ \\
\hline 2019 & $6.7 \%$ \\
\hline 2020 & $9.2 \%$ \\
\hline
\end{tabular}

Table.1. Poverty rate in India

In last three years, the rate of poverty is increased rapidly and food is also wasting. We can see the food waste statistics in the following table

\subsection{Food waste in India}

\subsubsection{Food Waste}

Food is the using up for resource for both animals and humans, but if we did not eat which is said to be food waste. The main cause of food waste is overproduction, over purchasing and rotten of foods. Some food waste occurs due to lack of transparency and inadequate supply facilities. More than

3.2.2 Food waste rate in India

More than $40 \%$ of food is manufactured which is expended carelessly with no purpose said by "The United Nations Food and Agriculture Organization (FAO)". 18.7 Kilograms of food is wasted daily in India.

\begin{tabular}{|c|c|}
\hline Year & Food Waste \\
\hline 2018 & 52 Million tons \\
\hline
\end{tabular}




\begin{tabular}{|l|l|}
\hline 2019 & 59 Million tons \\
\hline 2020 & 67 Million tons \\
\hline
\end{tabular}

Table.2. Food waste rate in India

By implementing this project, we can reduce the poverty rate in India. By reducing the poverty, we can increase the economic growth of our nation. The main cause of poverty is people who are not able to eat food due to financial status. In this Project waste food can send to orphanages and people who are not having funds to eat.

\section{Existing System Architecture}

- In Existing system, they only analyzed the food waste

- They did not categorized the food waste

- They did not make use of the cook item waste

- In that application, they cannot provide a facility to make use of this application to every organization

The following is the working model of the existing system (Figure.1)

Figure.1. Working model of existing system

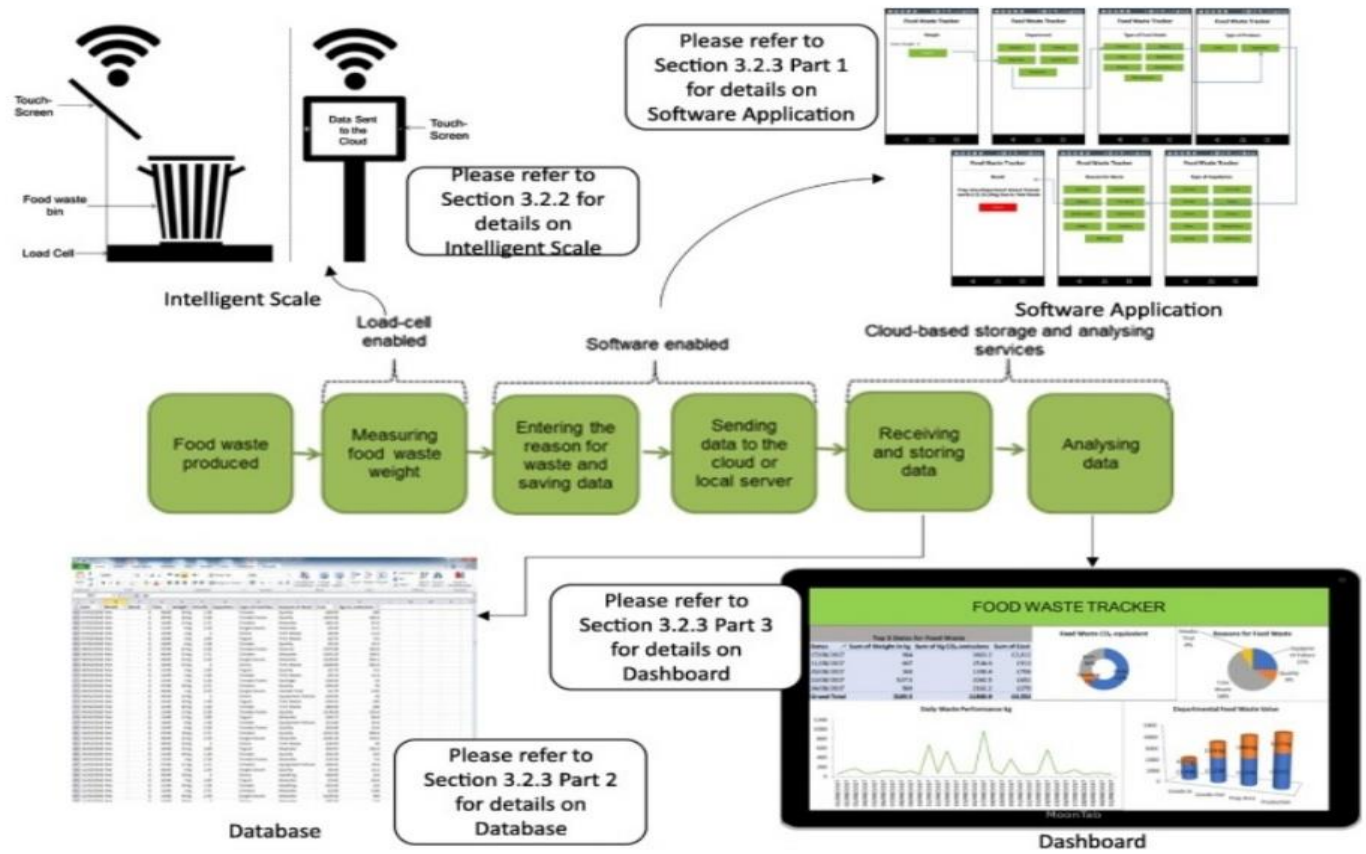

\section{Base Architecture}

Entity relationship diagram is a logical representation of the relational database. Entity relationship diagram shows how the entities and data are associated together. By seeing Entity relationship model, we can easily understand the architecture of any relational database.

The following is the base ER Diagram (Figure.2) of our application. We actually normalized it into third normal form, from this we actually eliminated the transitive dependencies of the tables. 


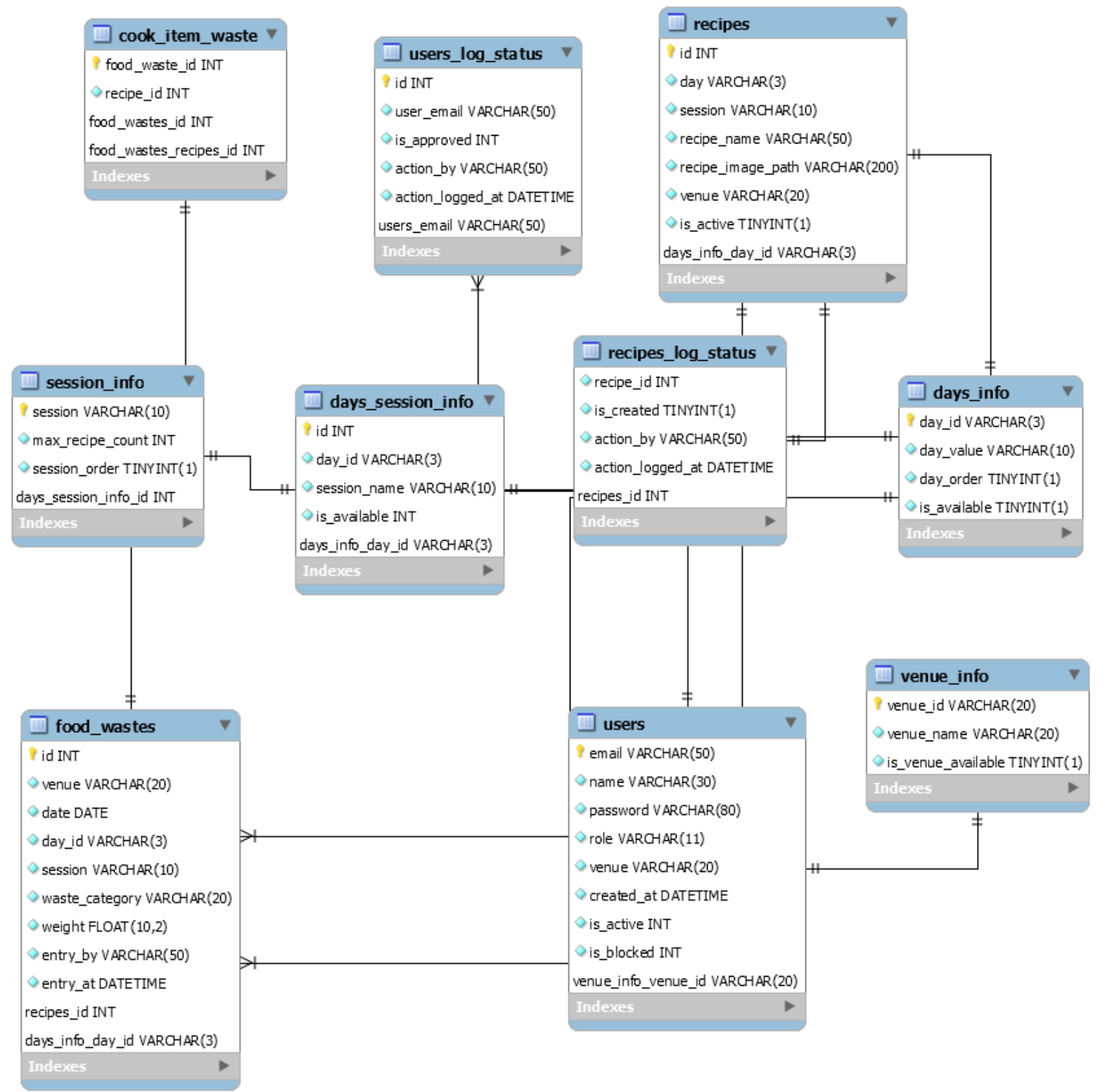

Figure.2. Base Schema of our database

\section{ADVANTAGES}

- Food can be reused; it will reduce the Food resources and it will be saved for future generations.

- The wasted food also used for Bio-degradable fertilization in Agriculture.

- By this process, we will help for Nation's growth.

- Also, it will avoid poverty in Orphanage.

- Food waste can be reduced.

\section{CONCLUSION}

Our important finding is that to reduce the food waste done by every colleges and schools every day and we achieved this through this Application and also we avoid poverty in Orphanage. 


\section{References}

1. T. Abraham, how $6 \mathrm{LFW}$ designers hope to raise $£ 1$ million with face coverings collection, the Telegraph.

2. D. Hoehn. Laso M. Margallo J. Ruiz-Salmon J. Cristóbal. Bala,L. Batlle-Bayer,P. Fullana-i-Palmer,A. Irabien,I.Vazquez-Rowe, Science of The Total Environment.

3. DrSarika Jain, David Newman: World Biogas Association

4. Ricardo Cepeda-Márquez, Kathrin Zeller: Cities Food \& Waste Programme.

5. https://hospitalityinsights.ehl.edu/food-waste-management-innovations

6. C., Demen-Meier, C., Gössling, S., \&Cornuz, C. (2018). Food waste management innovations in the foodservice industry. Waste Management.

7. Disposizioniconcernenti la donazione e la distribuzione di prodottialimentariefarmaceutici a fini di solidarietàsociale e per la limitazionedeglisprechi.

8. Gustavsson, J., Cederberg, C., Sonesson, U., van Otterdijk, R., Meybeck, A. Global food losses and food waste

9. HLPe report. Food losses and waste in the context of sustainable food systems. A report by The High-Level Panel of Experts on Food Security and Nutrition.

10. Murugesan, M., Thilagamani, S. ," Efficient anomaly detection in surveillance videos based on multi layer perception recurrent neural network", Journal of Microprocessors and Microsystems, Volume 79, Issue November 2020, https://doi.org/10.1016/j.micpro.2020.103303

11. Thilagamani, S., Nandhakumar, C. ." Implementing green revolution for organic plant forming using KNN-classification technique”, International Journal of Advanced Science and Technology, Volume 29, Isuue 7S, pp. 1707-1712

12. Singh, T.K., Cadwallader, K.R. In: Steele, $\quad$ R., (Ed.), Understanding and Measuring the Shelf- Life of Food. Food Science Australia, Australia, pp.171

13. Sert, S., Garrone, P., Melacini, M., Perego, A. Surplus food redistribution for social purposes: the case of coop Lombardia. In: Organizing Supply Chain Processes for Sustainable Innovation in the Agri-Food Industry, vol. 5. Emerald Group Publishing Limited.

14. Stevenson, M., Khan, S. Food Waste \& Food Loss: A Research Summary Conducted by R\&D Staff to Inform Internal WWF Strategy.

15. Segrè, A., Falasconi, L., Politano A., Vittuari M. SAVE FOOD: Global Initiative on Food Loss and Waste Reduction Background Paper on the Economics of Food Loss and Waste. Working paper. Food and Agriculture Organization of The United Nations, Rome.

16. Thilagamani, S., Shanti, N.," Gaussian and gabor filter approach for object segmentation”, Journal of Computing and Information Science in Engineering, 2014, 14(2), 021006, https://doi.org/10.1115/1.4026458

17. M. Aung, Y. Chang Traceability in a food supply chain: safety and quality perspectives Food Control.

18. S. Corrado, S. Sala Food waste accounting along global and European food supply chains: state of the art and outlook Waste Manage.

19. R. Darlington, S. Rahimifard A responsive demand management framework for the minimization of waste in convenience food manufacture Int. J. Comput. Integr. Manuf.

20. B. Derqui, T. Fayos, V. Fernandez Towards a more sustainable food supply chain: opening up invisible waste in food service Sustainability.

21. D. Evans, H. Campbell, A. Murcott A brief pre-history offood waste and the social sciences Sociol. Rev.

22. Rhagini, A., Thilagamani, S. ,"Women defence system for detecting interpersonal crimes",International Journal of Advanced Science and Technology, 2020, Volume 29,Issue7S, pp. 1669-1675

23. C. Göbel, N. Langen, A. Blumenthal, P. Teitscheid, G. Ritter Cutting food waste through cooperation along the food supply chain Sustainability.

24. S. Gunasekaran Automation of Food Processing G.V. Barbosa-Cánovas(Ed.), Food Engineering, EOLSS Publishers/ UNESCO.

25. Hanson, C., Lipinski, B., Robertson, K., Dias, D., Gavilan, I., Grevarath, P., Ritter, S., Fonseca, J., VanOtterdijk, R., Timmermans, T., Lomax, J., O'Connor, C., Dawe, A., Swannell, R., Berger, V., Reddy, M., Somogyi, D., Tran, B., Leach, B., Quested, T. Food Loss and Waste Accounting and Reporting Standard.

26. K.Deepa, S.Thilagamani, "Segmentation Techniques for Overlapped Latent Fingerprint Matching", International Journal of Innovative Technology and Exploring Engineering (IJITEE), ISSN: 2278-3075, Volume-8 Issue-12, October 2019. DOI: 10.35940/ijitee.L2863.1081219

27. M. Shafiee-Jood, X. Cai Reducing food loss and waste to enhance food security and environmental sustainability Environ. Sci. Technol.

28. Deepa, K., Kokila, M., Nandhini, A., Pavethra, A., Umadevi, M. "Rainfall prediction using CNN”, International Journal of Advanced Science and Technology, 2020, 29(7 Special Issue), pp. 1623-1627. http://sersc.org/journals/index.php/IJAST/article/view/10849

29. WWF,FoodWaste. Shttps://www.worldwildlife.org/initiatives/food-waste $>$.

30. J. Gustavsson, C. Cederberg, U. Sonesson Global Food Losses and Food Waste - Extent, Causes and Prevention FAO.

31. Santhi, P., Priyanka, T.,Smart India agricultural information reterival system, International Journal of Advanced Science and Technology, 2020, 29(7 Special Issue), pp. 1169-1175 
32. Beretta, C., Stoessel, F., Baier, U., \& Hellweg, S. Quantifying food losses and the potential for reduction in Switzerland(2013).

33. P. Pandiaraja, N Deepa 2019," A Novel Data Privacy-Preserving Protocol for Multi-data Users by using genetic algorithm”, Journal of Soft Computing , Springer, Volume 23 ,Issue 18, Pages 8539-8553

34. Curtis, K.R \& Slocum, S.L. The role of sustainability certification programs in reducing food waste in tourism(2016).

35. Gustavsson, J., Cederberg, C., Sonesson, U., Van Otterdijk, R., \&Meybeck, A. Global food losses and food waste(2011).

36. N Deepa , P. Pandiaraja, 2020 ," Hybrid Context Aware Recommendation System for E-Health Care by merkle hash tree from cloud using evolutionary algorithm”, Journal of Soft Computing , Springer, Volume 24 ,Issue 10, Pages 7149-7161.

37. Hyde, K., Smith A., Smith, M. \&Henningsson, S. (2001). The challenge of waste minimisation in the food and drink industry: a demonstration project in East Anglia, UK.

38. N Deepa, P. Pandiaraja, 2020, "E health care data privacy preserving efficient file retrieval from the cloud service provider using attribute based file encryption ", Journal of Ambient Intelligence and Humanized Computing, Springer, https://doi.org/10.1007/s12652-020-01911-5.

39. Muriana, C. (2017). A focus on the state of the art of food wastellosses issue and suggestions for future researches. Waste Management.

40. K Sumathi, P Pandiaraja 2019," Dynamic alternate buffer switching and congestion control in wireless multimedia sensor networks", Journal of Peer-to-Peer Networking and Applications, Springer, Volume 13,Issue 6,Pages 2001-2010

41. Parfitt, J., Barthel, M., \&Macnaughton, S. (2010). Food waste within food supply chains: quantification and potential for change to 2050. Philosophical Transactions of the Royal Society of London B: Biological Sciences.

42. Schneider, F. (2013). The evolution of food donation with respect to waste prevention. Waste Management.

43. Shankar, A., Pandiaraja, P., Sumathi, K., Stephan, T., Sharma, P. ,'” Privacy preserving E-voting cloud system based on ID based encryption " Journal of Peer-to-Peer Networking and Applications, Springer, https://doi.org/10.1007/s12083-020-00977-4.

44. FAO (2011) Global food losses and food waste - Extent, causes and prevention. FAO, Rome.

45. Kantor L, Lipton K, Manchester A, \& Oliveira V (1997) Estimating and addressing America's food losses. USDA Food Review.

46. Lipinski B, Hanson C, Lomax J et al (2013) Reducing Food Loss and Waste. Working Paper, Instalment 2 of Creating a Sustainable Food Future. World Resources Institute, Washington, DC. http://www.worldresourcesreport.org.

47. Schuster M, Torero M (2016) Toward a sustainable food system: Reducing food loss and waste. In: 2016 Global Food Policy Report. International Food Policy Research Institute (IFPRI), Washington, D.C.

48. Parfitt J, Barthel M, Macnaughton S (2010) Food waste within food supply chains: quantification and potential for change to 2050.

49. Eriksson, M., Osowski, C.P., Malefors, C., Björkman, J., \& Eriksson, E. (2017). Quantification of food waste in public catering services-A case study from a Swedish municipality.

50. World Resources Institute (2014). Reducing food loss and waste.

51. http://www.wri.org/blog/2014/10/reducing-food-loss-and-waste-overlooked-strategy-creating-sustainable-foodsystem. 